OPEN ACCESS

Edited by:

Carlos Alonso Escudero,

University of the Bío Bío, Chile

Reviewed by:

Rolando Juan Jose Ramirez,

University of Akron, United States

Marcelo González,

University of Concepcion, Chile

${ }^{*}$ Correspondence:

Teresa Tropea

teresa.tropea@manchester.ac.uk

Specialty section:

This article was submitted to

Vascular Physiology,

a section of the journal

Frontiers in Physiology

Received: 28 July 2020

Accepted: 15 October 2020

Published: 06 November 2020

Citation:

Tropea T, Greenwood SL,

Sibley CP and Cottrell EC (2020)

Grape Seed Extract Polyphenols Improve Resistance Artery Function

in Pregnant eNOS ${ }^{-1-}$ Mice.

Front. Physiol. 11:588000

doi: 10.3389/fphys.2020.588000

\section{Grape Seed Extract Polyphenols Improve Resistance Artery Function in Pregnant eNOS ${ }^{-/-}$Mice}

\author{
Teresa Tropea ${ }^{1,2 *}$, Susan L. Greenwood ${ }^{1,2}$, Colin P. Sibley ${ }^{1,2}$ and Elizabeth C. Cottrell1,2 \\ ${ }^{1}$ Division of Developmental Biology and Medicine, Faculty of Biology, Medicine and Health, Maternal and Fetal Health \\ Research Centre, University of Manchester, Manchester, United Kingdom, ${ }^{2}$ Manchester Academic Health Science Centre, \\ Manchester University NHS Foundation Trust, St. Mary's Hospital, Manchester, United Kingdom
}

Hypertension during pregnancy is a leading cause of maternal and fetal morbidity and mortality worldwide, increasing the risk of complications including preeclampsia, intracerebral hemorrhage and fetal growth restriction. Increased oxidative stress is known to contribute to poor vascular function; however, trials of antioxidant supplementation have raised concerns about fetal outcomes, including risk of low birthweight. Grape seed extract polyphenols (GSEP) have been suggested to promote cardiovascular protection, at least in part through antioxidant actions. We tested the hypothesis that administration of GSEP during pregnancy would reduce oxidative stress and improve resistance artery function with no detrimental effects on fetal growth, in an established model of maternal hypertension associated with vascular dysfunction, the endothelial NO synthase knockout (eNOS ${ }^{-/}$) mouse. Pregnant C57BL/6J (WT) and eNOS ${ }^{-/-}$mice received either GSEP (200 mg/kg/day) or drinking water, between gestational (GD) day 10.5 and GD18.5. At GD17.5, maternal systolic blood pressure (SBP) was measured; at GD18.5, maternal malondialdehyde (MDA) concentrations, vascular function of aortic, mesenteric, uterine and posterior cerebral arteries was assessed, and fetal outcome evaluated. GSEP reduced maternal SBP $(P<0.01)$ and plasma MDA concentrations $(P<0.01)$ in eNOS $-1-$ mice. Whilst there was no effect of GSEP on vascular reactivity of aortas, GSEP improved endothelial-dependent relaxation in mesenteric and uterine arteries of eNOS ${ }^{-1-}$ mice $(P<0.05$ and $P<0.001$, respectively) and normalized lumen diameters of pressurized posterior cerebral arteries in eNOS ${ }^{-1-}$ mice $(P<0.001)$. Supplementation with GSEP had no effect in WT mice and did not affect fetal outcomes in either genotype. Our data suggest that GSEP improve resistance artery function, potentially through antioxidant actions, and provide a basis to further investigate these beneficial effects including in the prevention of intracerebral hemorrhage. Maternal supplementation with GSEP may be a safe intervention to improve outcomes in pregnancies associated with hypertension and vascular dysfunction.

Keywords: resistance artery, pregnancy, hypertension, polyphenols, grape seed 


\section{INTRODUCTION}

Pregnancies complicated by chronic hypertension have an increased risk of adverse perinatal outcomes (Gilbert et al., 2007; Chappell et al., 2008), including fetal growth restriction (FGR), preterm delivery, and perinatal death (Jain, 1997; Sibai et al., 1998; Bramham et al., 2014), as well as life-threatening maternal consequences, such as preeclampsia $(\mathrm{PE})$, superimposed $\mathrm{PE}$, eclampsia, cerebral hemorrhage, and maternal death (Sibai, 2002; Bateman et al., 2006; Bellamy et al., 2007; Moodley, 2008). By definition, chronic hypertension is the diagnosis of elevated blood pressure of $\geq 140 \mathrm{mmHg}$ systolic and/or $90 \mathrm{~mm} \mathrm{Hg}$ diastolic, before pregnancy or before 20 weeks of gestation (Sibai, 2002). Chronic hypertension affects $1-5 \%$ of pregnancies (Haddad and Sibai, 1999; Livingston and Sibai, 2001; Bramham et al., 2014; Sutton et al., 2018), with prevalence increasing with increasing maternal age (Maducolil et al., 2020).

Amongst all of the detrimental outcomes, intracerebral hemorrhage is the main cause of maternal mortality in hypertensive disorders of pregnancy worldwide (Ascanio et al., 2019; Conti-Ramsden et al., 2019). Analysis of the global burden of hypertension in pregnancy estimates the highest prevalence rates to be in developing countries (Noubiap et al., 2019).

In the absence of complications, normotensive pregnant women undergo a physiological decrease in blood pressure toward the end of the first trimester, secondary to increased vasodilation; women with chronic hypertension do not always experience this maternal cardiovascular adaptation (Seely and Ecker, 2014). During pregnancy, the endothelium plays a major role in regulating changes in vascular smooth muscle tone in the uterine and systemic circulation, by balancing the release of both endogenous vasodilators and vasoconstrictors (Tanbe and Khalil, 2010). Abnormalities in the bioavailability and bioactivity of these factors, particularly the vasodilator nitric oxide (NO), impairs endothelium-dependent vasodilation, which results in endothelial dysfunction (Albrecht et al., 2003; Landmesser et al., 2004). Moreover, the high nutrient and energy requirements for fetal growth makes the placenta a highly metabolically active organ (Vaughan and Fowden, 2016), which generates reactive oxygen species (ROS) that contribute to maternal systemic oxidative stress (Myatt, 2010). Excessive ROS may cause or exacerbate endothelial dysfunction (Lum and Roebuck, 2001) and predispose to the development of subsequent maternal cardiovascular disorders, including PE (Miranda Guisado et al., 2012; Schoots et al., 2018; Chiarello et al., 2020; San Juan-Reyes et al., 2020).

In addition to antihypertensive medications to manage maternal blood pressure, interventions aimed at targeting the increased oxidative stress may be able to reduce secondary consequences and prevent worsening of maternal disease. Evidence from some clinical trials (Poston et al., 2006) do not encourage maternal supplementation with antioxidants such as vitamin $\mathrm{C}$ and vitamin $\mathrm{E}$, as these interventions have not been shown to improve maternal health outcomes, and have also been associated with increased rates of low-birthweight babies. Trials aimed at improving pregnancy outcomes in other highrisk groups have shown benefits with the use of supplements containing high levels of polyphenols. Maternal administration of a catechin-rich dietary supplement (epigallocatechin 3-gallate, EGCG), has been demonstrated to improve both maternal and neonatal outcomes in pregnancies affected by gestational diabetes mellitus, including neonatal weight at birth (Zhang et al., 2017), and data from a recent randomized placebocontrolled, double-blind pilot study (Matthews et al., 2019), have provided preliminary evidence of in utero neuroprotective effects of polyphenol-rich pomegranate juice, in newborns from FGR pregnancies. These approaches may be of benefit in hypertensive pregnancies, though data are currently lacking.

Grape seed extract polyphenols (GSEP), a complex mixture mainly composed of polymers of catechin (Shi et al., 2003), have a great potential for protection against oxidative stress (Bagchi et al., 2000). Evidence from previous studies in nonpregnant humans, non-pregnant and pregnant animals suggests that commercially available GSEP provide a natural source of antioxidants, which can protect endothelial function and reduce blood pressure (Oueslati et al., 2016; Park et al., 2016; Pons et al., 2016; Zhu et al., 2018). These beneficial effects, in addition to improved cardiovascular and kidney remodeling, have been previously demonstrated in pregnant mice, using the $\mathrm{N} \omega$-Nitrol-arginine methyl ester (L-NAME)-induced hypertension model (Zhu et al., 2018). However, to date there have been no reports on the effects of GSEP supplementation in pregnancy on maternal resistance artery (diameter $<300 \mu \mathrm{m}$ ) function or pregnancy outcomes, in an animal model of chronic hypertension.

Hence, this study addressed the hypothesis that administration of GSEP during pregnancy would reduce oxidative stress and improve resistance artery function to protect the maternal vascular system, in an established model of maternal hypertension associated with vascular dysfunction, the endothelial NO synthase knockout $\left(\mathrm{eNOS}^{-/-}\right.$) mouse (Kusinski et al., 2012).

\section{MATERIALS AND METHODS}

\section{Experimental Animals}

The present study was performed in accordance with the UK Animals (Scientific Procedures) Act of 1986, under Home Office Project Licenses PPL 40/3385 and P9755892D. All protocols were approved by the Local Animal Welfare and Ethical Review Board of the University of Manchester. Endothelial NO synthase knockout (eNOS ${ }^{-/}$) mice (stock number 002684), were purchased from Jackson Laboratories (Bar Harbor, ME, United States). C57BL/6J mice (Charles River Laboratories), the background strain for $\mathrm{eNOS}^{-/-}$mice, were used as wildtype (WT) control mice. All animals were housed in individually ventilated cages maintained under a constant $12 \mathrm{~h}$ light/dark cycle at $21-23^{\circ} \mathrm{C}$, and had free access to food (BK001 diet, Special Dietary Services, United Kingdom) and water (Hydropac, Lab products Inc., Seaford, DE, United States). Female mice (10-18 weeks old) were mated overnight with genotype-matched male mice and the presence of a copulation plug on the following morning was defined as gestational day (GD) 0.5 (estimated term, GD19.5). At GD10.5, mice were weighed and randomly assigned to receive either grape seed extract polyphenols (GSEP; Meganatural-BP Grape Seed Extract, Polyphenolics, Madera, 
CA $)^{1}, 200 \mathrm{mg} / \mathrm{kg} /$ day solubilized in the drinking water, to deliver an amount equivalent to a human dose of $1 \mathrm{~g} / \mathrm{d}$ (according to Food and Drug Administration criteria for converting drug equivalent dosages across species), or drinking water alone for the remainder of pregnancy. Fresh bottles were made up daily and fluid consumption was recorded. Supplementation with GSEP was started at mid-gestation, when the mature mouse placenta is formed, but continues to grow ( GD10.5; Woods et al., 2018). Additionally, this gestational age is analogous to the second trimester of human pregnancy, when early FGR can be diagnosed and therapeutic intervention initiated. At GD18.5, animals were sacrificed by cervical dislocation; maternal blood samples were collected and maternal and fetal tissues harvested.

\section{Systolic Blood Pressure and Heart Rate Measurements}

Systolic blood pressure (SBP) and heart rate (HR) were determined in a subset of pregnant mice prior to assignment of the treatments and at GD17.5, using a validated non-invasive tailcuff method (LE5001; Pan Lab, Spain). A small rodent restraining tube was placed on a thermo-pad mat. Mice were acclimatized to reduce stress before measurements were taken and once in the restraining tube, they were secured with the tail exposed for the tail cuff occlusion device and pulse transducer. SBP and HR were recorded 5-10 min after placing the devices on the tail. A total of 12-18 readings was taken within approximately $45 \mathrm{~min}$ and averaged for each individual mouse.

\section{Measurement of Lipid Peroxidation in Maternal Plasma}

Lipid peroxidation was evaluated as an indicator of oxidative stress in maternal plasma. Blood samples were collected into capillary tubes (Microvette CB 300, Sarstedt) and immediately centrifuged at 5,000 rpm for $5 \mathrm{~min}$; plasma was stored at $-80^{\circ} \mathrm{C}$ until thiobarbituric acid-reactive substances (TBARS) assay was performed according to the manufacturer's instructions (Cayman, cat. no 700870). Malondialdehyde (MDA) is a byproduct of lipid peroxidation that reacts with thiobarbituric acid (TBA). Herein, the TBARS assay was used to measure MDA-TBA adduct, thus providing an estimate of MDA concentrations in maternal plasma (expressed in $\mathrm{nM}$ ).

\section{Wire Myography}

Maternal aorta, mesentery and uterus were rapidly removed and collected in ice-cold-physiological saline solution (PSS; in $\mathrm{mM}, 117 \mathrm{NaCl}, 25 \mathrm{NaHCO}_{3}, 4.69 \mathrm{KCl}, 2.4 \mathrm{MgSO}_{4}, 1.6$ $\mathrm{CaCl}_{2}, 1.18 \mathrm{KH}_{2} \mathrm{PO}_{4}, 6.05$ glucose, 0.034 EDTA; $\mathrm{pH} 7.4$ ) for ex vivo assessment of tone generation, using wire myography. Abdominal aortic, third-order mesenteric arteries and main branch uterine arteries were dissected free from perivascular connective and adipose tissue in ice-cold PSS. Vessels were cut in short segments (approximately $2 \mathrm{~mm}$ in length), mounted on two $40 \mu \mathrm{m}$ steel wires in a myograph chamber (Model $620 \mathrm{M}$,

${ }^{1}$ http://www.polyphenolics.com/wp-content/uploads/2017/08/3-MegaNaturalBP-Brochure.pdf
Danish MyoTechnologies, Denmark) and immersed in $6 \mathrm{~mL}$ of $5 \% \mathrm{CO}_{2} / 20 \%$ oxygen $/ 75 \%$ nitrogen gassed PSS, at $37^{\circ} \mathrm{C}$. Vessels were then normalized to 0.9 of luminal pressure $(\mathrm{L})_{13.3}$ $\mathrm{kPa}$, through a series of stepwise stretches to determine their optimal resting tension (Mulvany and Halpern, 1977) and equilibrated for $20 \mathrm{~min}$. Post-equilibration, vascular segments underwent two separate exposures to a depolarizing solution (KPSS; $120 \mathrm{mM} \mathrm{KCl}$ in PSS, equimolar substitution of $\mathrm{KCl}$ for $\mathrm{NaCl}$ ). After washing with PSS, a concentration-response curve to the thromboxane mimetic U46619 $\left(10^{-10}-2 \times 10^{-6} \mathrm{M}\right.$, Cayman Chemicals) was assessed and used to obtain the $\mathrm{EC}_{80}$ concentration of U46619. Endothelium-dependent relaxation to acetylcholine (ACh, $10^{-10}-10^{-5} \mathrm{M}$ ) and endotheliumindependent relaxation to the $\mathrm{NO}$ donor, sodium nitroprusside (SNP, $10^{-10}-10^{-5} \mathrm{M}$ ) were assessed in vessels pre-constricted with an $\mathrm{EC}_{80}$ dose of U46619. Vessel tension produced by maximal depolarization to KPSS and concentration-response curve to U46619 was expressed as active effective pressure in $\mathrm{kPa}$; Cmax was the maximum effect of the dose-response constriction with U46619. Concentration-response relaxation to ACh and SNP was expressed as a remaining percentage from the level of pre-constriction achieved with an $\mathrm{EC}_{80}$ dose of U46619. Maximum relaxation (Rmax) to ACh and SNP was expressed as a percentage of the maximum effect of the dose-response. Effects on the sensitivity (the molar concentration of U46619, ACh and SNP causing $50 \%$ of the maximal response), were expressed as logarithm $\left(\log \mathrm{EC}_{50}\right)$.

Dose-response effects of the extract to induce vasorelaxation were confirmed in a separate set of wire myography experiments performed in human chorionic plate blood vessels, to confirm bioreactivity of the batch of GSEP, prior to the commencement of the present study (data not shown).

\section{Pressure Myography}

Maternal brains were quickly removed and placed in ice-cold PSS. Second-order branches of posterior cerebral arteries were gently dissected and cleared of connective tissue. Arterial segments (approximately $2 \mathrm{~mm}$ long) were mounted on two glass cannulas within a chamber for small-vessel pressure myography studies, with both ends secured, to assess diameter changes as previously described (Tropea et al., 2015). Before starting the experiment, intraluminal pressure was increased through the proximal cannula using a servo-null pressure system (Living Systems Instrumentation) to remove the intraluminal content; then, the distal cannula was closed off to avoid any loss of pressure. Arteries with no constant pressure were discarded. Lumen diameter was visualized by an inverted microscope connected to a CCD camera and a monitor and was continuously recorded with a dataacquisition software (LabChart, AD Instruments).

All arteries were continuously superfused with warmed PSS at $37^{\circ} \mathrm{C}$, aerated with $5 \% \mathrm{CO}_{2} / 20 \%$ oxygen $/ 75 \%$ nitrogen and pressurized to $50 \mathrm{mmHg}$. Following $45 \mathrm{~min}$ of equilibration under no-flow conditions, artery viability was evaluated by superfusing with KPSS. After washing with PSS, changes in lumen diameter were monitored by increasing intraluminal pressure from 10 to $110 \mathrm{mmHg}$ (20 $\mathrm{mmHg}$ increments), allowing arteries to equilibrate to steady-state at each pressure. 
Passive measurements of lumen diameter, distensibility and wall stress were obtained in fully dilated arteries by superfusing with PSS containing diltiazem $\left(10^{-5} \mathrm{M}\right)$ and papaverine $\left(10^{-4}\right.$ M) at each pressure, as previously described (Cipolla et al., 2006).

\section{Drugs and Chemicals}

Chemicals and reagents used in the present study were purchased from Sigma Aldrich, unless otherwise stated.

\section{Data Analysis}

Data are expressed as mean \pm SD (for parametric data) or median and range (for non-parametric data; fluid intake, litter size, resorptions) and $\mathrm{N}$ is the number of mice used. Nonparametric data were transformed prior to analysis using 2way ANOVA, which included genotype and GSEP treatment as independent variables, with Sidak's post-hoc testing and adjustment for multiple comparisons, as appropriate, performed using Prism 8 software (GraphPad Software Inc., La Jolla, CA). Differences were considered significant at $P<0.05$.

\section{RESULTS}

\section{GSEP Supplementation Had No Effect on Fluid Consumption or Maternal Body Weight in Pregnant Mice}

There were no differences in maternal fluid intake following GSEP treatment compared with water controls in either WT or $\mathrm{eNOS}^{-/-}$mice [WT $\mathrm{H}_{2} \mathrm{O}, 9.8$ (6.1-25.7); WT GSEP, 8.1
(5.8-21.8); eNOS$^{-/-} \mathrm{H}_{2} \mathrm{O}, 8.6$ (6.1-11.4); eNOS $^{-/-}$GSEP, 9.9 (7.5-11.5); mL/day]. Maternal body weight (BW) was not different between genotypes at GD0.5, or at GD10.5, before the commencement of the treatment (Table 1). WT mice were significantly heavier than eNOS $-/-$ mice at GD18.5 $(P<0.01$, Table 1), but the treatment with GSEP had no effect on maternal BW (Table 1).

\section{Treatment With GSEP Reduced Maternal Systolic Blood Pressure and Had No Effect on Heart Rate in eNOS-/- Mice}

Prior to the start of treatment at GD10.5, eNOS ${ }^{-/}$mice showed significantly higher SBP (WT, $115.0 \pm 4.7$, eNOS ${ }^{-/}$, $141.6 \pm 10.1 \mathrm{mmHg} ; P<0.001)$ and lower HR (WT, 635.9 \pm 40.0 , $\mathrm{eNOS}^{-/-}, 554.9 \pm 64.5$ beats/min; $\left.P<0.01\right)$ compared with WT. Supplementation with GSEP significantly lowered maternal SBP in eNOS ${ }^{-/-}$mice (effect of treatment, $P<0.01$; Figure 1A), but did not change SBP in WT animals, and had no effect on HR in either genotype (Figure 1B) at GD17.5. A genotype effect on HR remained at GD17.5 $(P<0.05$; Figure 1B).

\section{GSEP Supplementation Reduced Levels of Oxidative Stress in Maternal Plasma of eNOS $-1-$ Mice}

MDA concentrations detected in maternal plasma were significantly increased in eNOS ${ }^{-/-}$mice compared with WT $\mathrm{H}_{2} \mathrm{O}$ mice $(P<0.05$; Figure 2). Supplementation with GSEP had significant treatment $(P<0.01$; Figure 2$)$ and interaction

TABLE 1 | Maternal body weight.

\begin{tabular}{|c|c|c|c|c|c|c|c|}
\hline \multirow{2}{*}{$\begin{array}{l}\text { Genotype } \\
\text { Treatment }\end{array}$} & \multicolumn{2}{|c|}{ WT } & \multicolumn{2}{|c|}{ eNOS$^{-1-}$} & \multicolumn{3}{|c|}{ Effects } \\
\hline & $\mathrm{H}_{2} \mathrm{O}$ & GSEP & $\mathrm{H}_{2} \mathrm{O}$ & GSEP & Treat & Gen & Int \\
\hline BW at GD0.5 (g) & $21.5 \pm 1.6$ & $21.3 \pm 1.0$ & $19.9 \pm 1.4$ & $19.9 \pm 1.0$ & NS & NS & NS \\
\hline BW at GD10.5 (g) & $25.6 \pm 2.4$ & $25.4 \pm 1.0$ & $23.6 \pm 1.6$ & $23.6 \pm 1.2$ & NS & NS & NS \\
\hline BW at GD18.5 (g) & $38.5 \pm 3.6$ & $38.7 \pm 2.6$ & $34.9 \pm 4.1$ & $34.1 \pm 2.2$ & NS & \#\# & NS \\
\hline
\end{tabular}

Data are expressed as mean $\pm S D$. Treat, effect of treatment; Gen, effect of genotype; Int, interaction between genotype and treatment. \#\# $P<0.01$ WT vs. eNOS ${ }^{-1-}$; NS, not significant. $N=8-11$ dams per group.
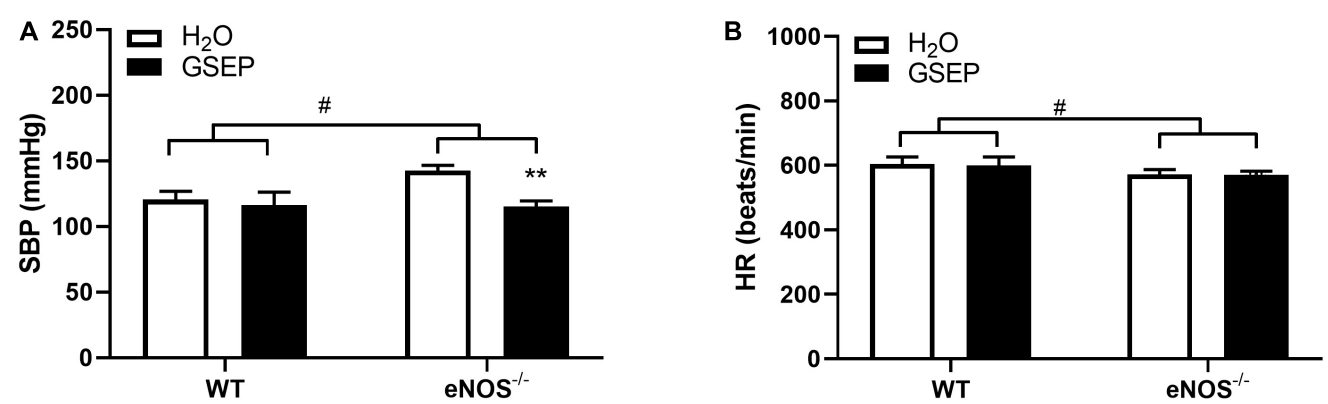

FIGURE 1 | GSEP supplementation lowers systolic blood pressure without affecting heart rate in eNOS ${ }^{-/-}$mice at GD17.5. In eNOS-/- mice, systolic blood pressure (SBP) was significantly higher compared with WT animals, and was reduced by supplementation with GSEP (A). Heart rate (HR) was significantly lower in eNOS $^{-/-}$mice compared with WT animals but was unaffected by GSEP treatment (B). ${ }^{\#} P<0.05$ eNOS ${ }^{-/-}$vs. WT; ${ }^{\star \star} P<0.01$ GSEP vs. $\mathrm{H}_{2} \mathrm{O}$. N $=3-4$ dams per group. 


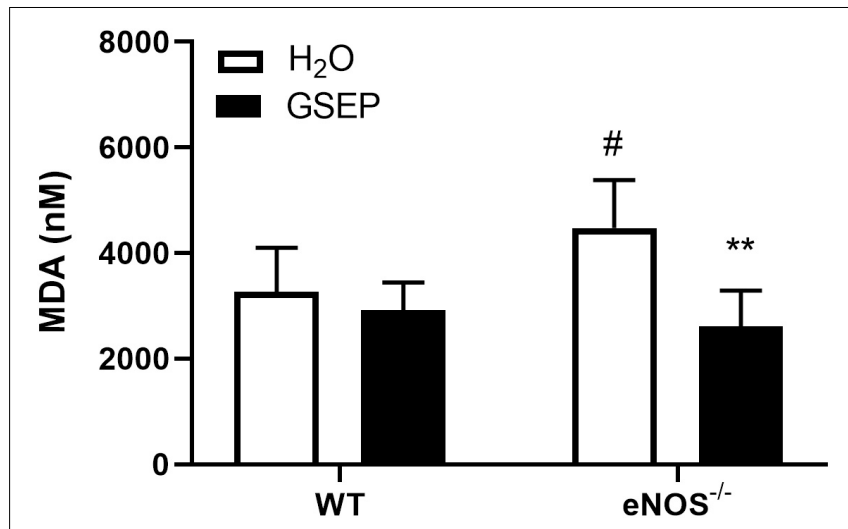

FIGURE 2 | Treatment with GSEP decreases oxidative stress in maternal plasma of eNOS ${ }^{-/-}$mice. Concentrations of malondialdehyde (MDA) were significantly higher in maternal plasma of $\mathrm{NOS}^{-/-}$mice compared with WT $\mathrm{H}_{2} \mathrm{O}$ mice and were significantly reduced in $\mathrm{eNOS}^{-/-}$mice treated with GSEP. ${ }^{\#} P<0.05$ eNOS $^{-/-}$vs. WT $\mathrm{H}_{2} \mathrm{O}$; ${ }^{* \star} P<0.01$ GSEP vs. $\mathrm{H}_{2} \mathrm{O} . \mathrm{N}=5-6$ dams per group.

effects $(P<0.05$; Figure 2$)$ on MDA levels, significantly reducing the marker of lipid peroxidation in $\mathrm{eNOS}^{-/-}$mice only $(P<0.01$; Figure 2).

\section{GSEP Supplementation Induced Changes in Vascular Reactivity of Maternal Aortic, Mesenteric, and Uterine Arteries of eNOS $-/-$ Mice}

Following exposure to the maximally depolarizing potassium solution, aortas of $\mathrm{eNOS}^{-/-}$mice developed greater tension than WT (effect of genotype, $P<0.001$; Figure 3A), whereas mesenteric and uterine arteries showed reduced vascular contractility to KPSS compared with WT (effect of genotype, $P<0.01, P<0.001$, respectively; Figures 3B,C); treatment with GSEP had no effect on KPSS constriction (Figure 3).

Both constriction and sensitivity to the thromboxane mimetic U46619 were higher in aortas of $\mathrm{eNOS}^{-/-}$mice compared with WT mice (Cmax: WT, $13.3 \pm 2.8$, eNOS ${ }^{-/}-, 14.7 \pm 2.5 \mathrm{kPa}$; effect of genotype, $P=0.053$; $\log \mathrm{EC}_{50}$ : WT, $-7.91 \pm 0.6$, eNOS ${ }^{-/}$, $-8.260 \pm 0.1$; effect of genotype, $P<0.05$; Figure 4A); there were no differences in mesenteric arteries (Figure 4D), whereas uterine arteries of $\mathrm{eNOS}^{-/-}$mice were more sensitive than WT mice to U46619 ( $\log \mathrm{EC}_{50}$ : WT, $-7.40 \pm 0.6, \mathrm{eNOS}^{-/-},-7.92 \pm 0.4$; effect of genotype, $P<0.01$; Figure 4G). Treatment with GSEP did not have a significant effect on constriction to U46619 in either aortas (Figures 4B,C) or mesenteric arteries (Figures 4E,F) of both genotypes, or in uterine arteries of WT animals (Figure $4 \mathbf{H}$ ), but significantly increased vascular reactivity to the thromboxane mimetic in uterine arteries of $\mathrm{eNOS}^{-/-}$mice compared with $\mathrm{H}_{2} \mathrm{O}$ controls $(P<0.0001$; Figure $4 \mathrm{I})$.

There was no endothelium-dependent relaxation to ACh in aortas of $\mathrm{eNOS}^{-/-}$mice compared with WT mice (Figure 5A) and treatment with GSEP did not affect relaxation to ACh in aortas of both WT and $\mathrm{eNOS}^{-/}$mice (Figures 5B,C). Endothelium-dependent relaxation was significantly reduced in both mesenteric and uterine arteries of eNOS ${ }^{-/-}$mice compared with WT mice (Rmax: mesenteric arteries, WT, $81.9 \pm 10.0$, eNOS $^{-/}$, $49.7 \pm 18.1 \%$; uterine arteries, WT, $96.4 \pm 2.2$, eNOS $^{-/}$, $52.2 \pm 17.5 \%$; effect of genotype, $P<0.0001$ both; Figures 5D,G), and sensitivity was lower only in uterine arteries of $\mathrm{eNOS}^{-/}$mice compared with WT mice (Log $\mathrm{EC}_{50}$ : WT, $-7.54 \pm 0.7$, eNOS $^{-/-},-6.41 \pm 0.4$; effect of genotype, $P<0.0001$; Figure 5G). Treatment with GSEP had no effect on ACh responses in either mesenteric or uterine arteries of WT animals (Figures 5E,H), but significantly enhanced endotheliumdependent relaxation in both of these vascular beds in eNOS ${ }^{-/-}$ mice $(P<0.05, P<0.001 ;$ mesenteric and uterine arteries, respectively; Figures 5F,I).

Endothelium-independent relaxation and sensitivity to the NO donor SNP were significantly increased in aortas of $\mathrm{NOS}^{-/-}$ mice compared with WT mice (Rmax: WT, $73.4 \pm 20.7$, eNOS $^{-/}$, $85.6 \pm 12.1 \%$; effect of genotype, $P<0.01$; Log $\mathrm{EC}_{50}$ : WT, $-7.43 \pm 0.4, \mathrm{eNOS}^{-/-},-7.86 \pm 0.4$; effect of genotype, $P<0.05$; Figure 6A). There were no genotypedifferences in response to SNP in either mesenteric or uterine arteries (Figures 6D,G). Treatment with GSEP did not affect aortas of either genotype (Figures 6B,C), or uterine arteries of WT controls (Figure 6H). GSEP had a slight but significant effect to enhance vascular smooth muscle sensitivity to SNP in mesenteric arteries of WT and $\mathrm{NNOS}^{-/-}$mice $\left(\log \mathrm{EC}_{50}\right.$ : WT $\mathrm{H}_{2} \mathrm{O},-7.52 \pm 0.3$, WT GSEP, $-7.75 \pm 0.3$, eNOS $-/-\mathrm{H}_{2} \mathrm{O}$ $-7.51 \pm 0.4$, eNOS $^{-/}$GSEP, $-7.77 \pm 0.4$; effect of treatment,
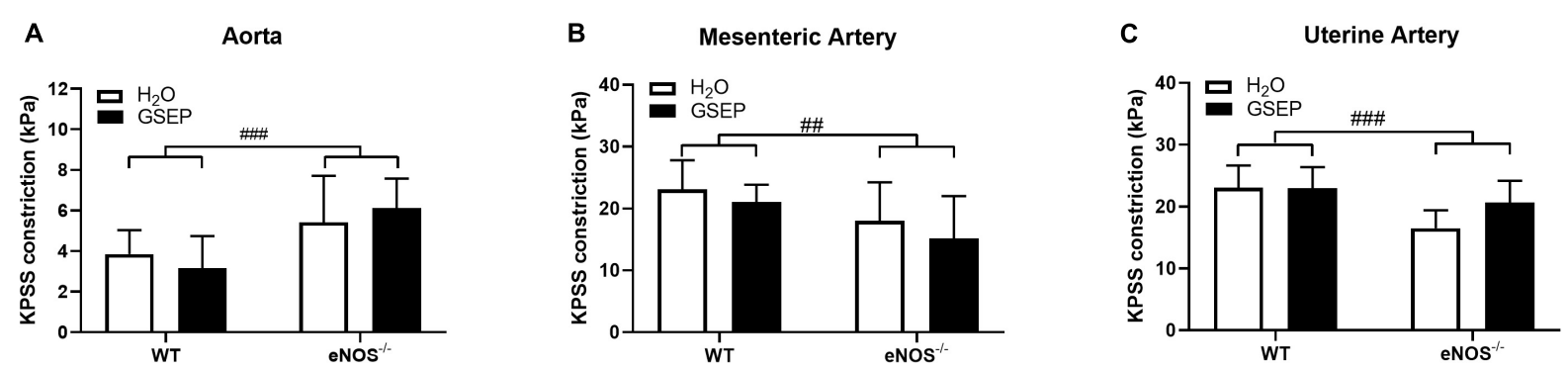

FIGURE 3 | Supplementation with GSEP has no effect on maximal smooth muscle depolarization. Treatment with GSEP did not alter constriction of either aortas (A), mesenteric (B), or uterine (C) arteries in response to a maximal smooth muscle depolarization induced by KPSS in WT or eNOS ${ }^{-/-}$mice. ${ }^{\#} P<0.01$, \#\#\# $P<0.001$ eNOS ${ }^{-/-}$vs. WT. $N=6-11$ dams per group. 


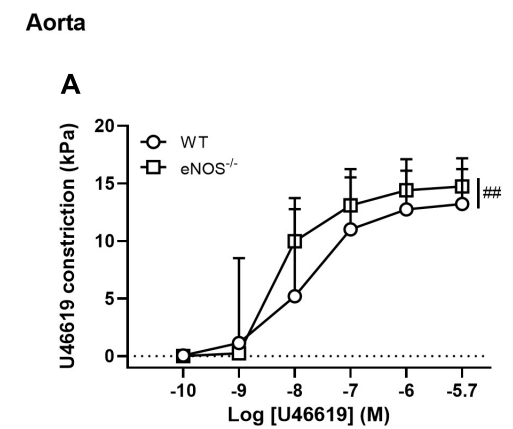

Mesenteric Artery

D

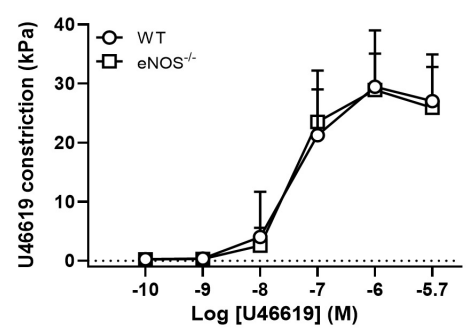

Uterine Artery

G

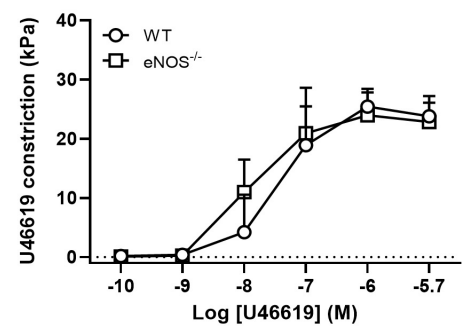

B

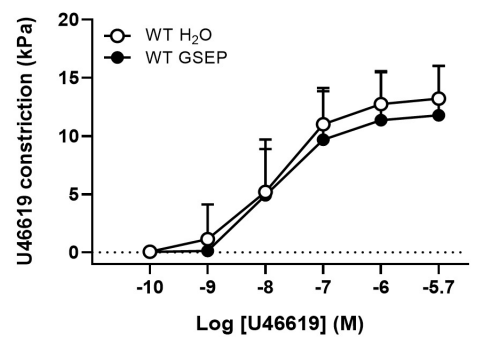

E

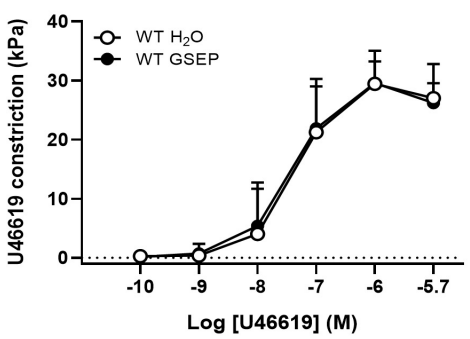

H

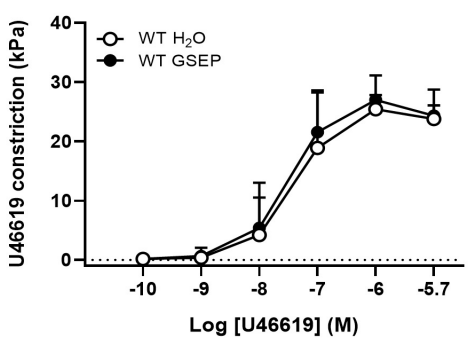

C

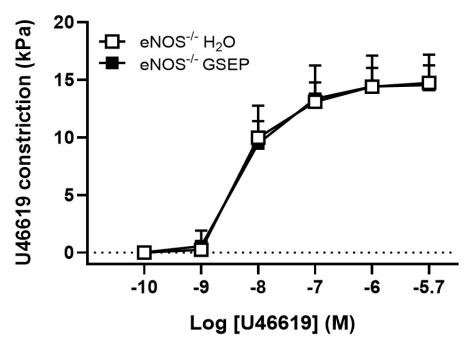

$\mathbf{F}$

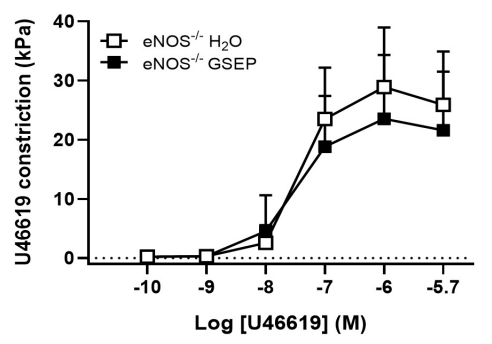

I

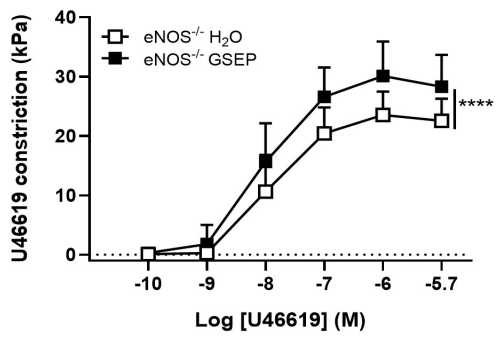

FIGURE 4 | GSEP supplementation increases thromboxane mimetic-induced constriction of uterine arteries in eNOS ${ }^{-/-}$mice. Aortas of eNOS ${ }^{-/-}$mice (A), but not mesenteric (D) or uterine arteries (G), showed significantly higher constriction to U46619 compared with WT controls. Maternal GSEP supplementation did not affect constriction in response to U46619 of either aortas $\mathbf{( B , C )}$ or mesenteric arteries $\mathbf{( E , F ) ~ i n ~ W T ~ o r ~ e N O S ~}{ }^{-1-}$ mice. In uterine arteries, GSEP treatment had no effect on U46619-induced constriction in WT (H) but significantly increased vasoconstriction in eNOS ${ }^{-1-}$ mice (I). ${ }^{\# \#} P<0.01$ eNOS ${ }^{-/-}$vs. WT; ${ }^{* \star \star \star} P<0.0001$ GSEP vs. $\mathrm{H}_{2} \mathrm{O} . \mathrm{N}=6-11$ dams per group.

$P<0.05$; Figures 6E,F), and relaxation in response to SNP in uterine arteries of $\mathrm{eNOS}^{-/-}$mice $(P<0.05$; Figure 6I).

\section{GSEP Supplementation Prevented Pressure-Induced Increase in Diameter of Posterior Cerebral Arteries in eNOS $-1-$ Mice}

A stepwise increase in intraluminal pressure $(10-110 \mathrm{mmHg}$ ), revealed that posterior cerebral arteries of $\mathrm{eNOS}^{-/-}$mice display larger lumen diameters than WT mice (effect of genotype on steady-state diameters across pressure range, $P<0.01$; Figure 7A). Maternal treatment with GSEP did not affect lumen diameters of WT mice (Figure 7B), but significantly reduced diameters of posterior cerebral arteries of $\mathrm{eNOS}^{-/-}$ mice $(P<0.001$; Figure 7C). GSEP reduced distensibility (overall effect of treatment, $P<0.05$; Figure 7D), whereas wall stress was unaltered (Figure 7E), at the highest pressure assessed (110 $\mathrm{mmHg})$.

\section{Supplementation With GSEP Had No Effect on Pregnancy Outcomes}

eNOS $^{-/-}$mice had significantly smaller fetuses compared with WT mice $(P<0.0001$; Table 2). There were no significant differences in placental weights, litter size or number of resorptions between genotypes, and maternal treatment with GSEP did not alter fetal outcomes in WT or eNOS ${ }^{-/-}$mice at GD18.5 (Table 2).

\section{DISCUSSION}

Chronic hypertension in pregnancy is associated with significant short- and long-term adverse maternal and fetal consequences. 


\section{Aorta}
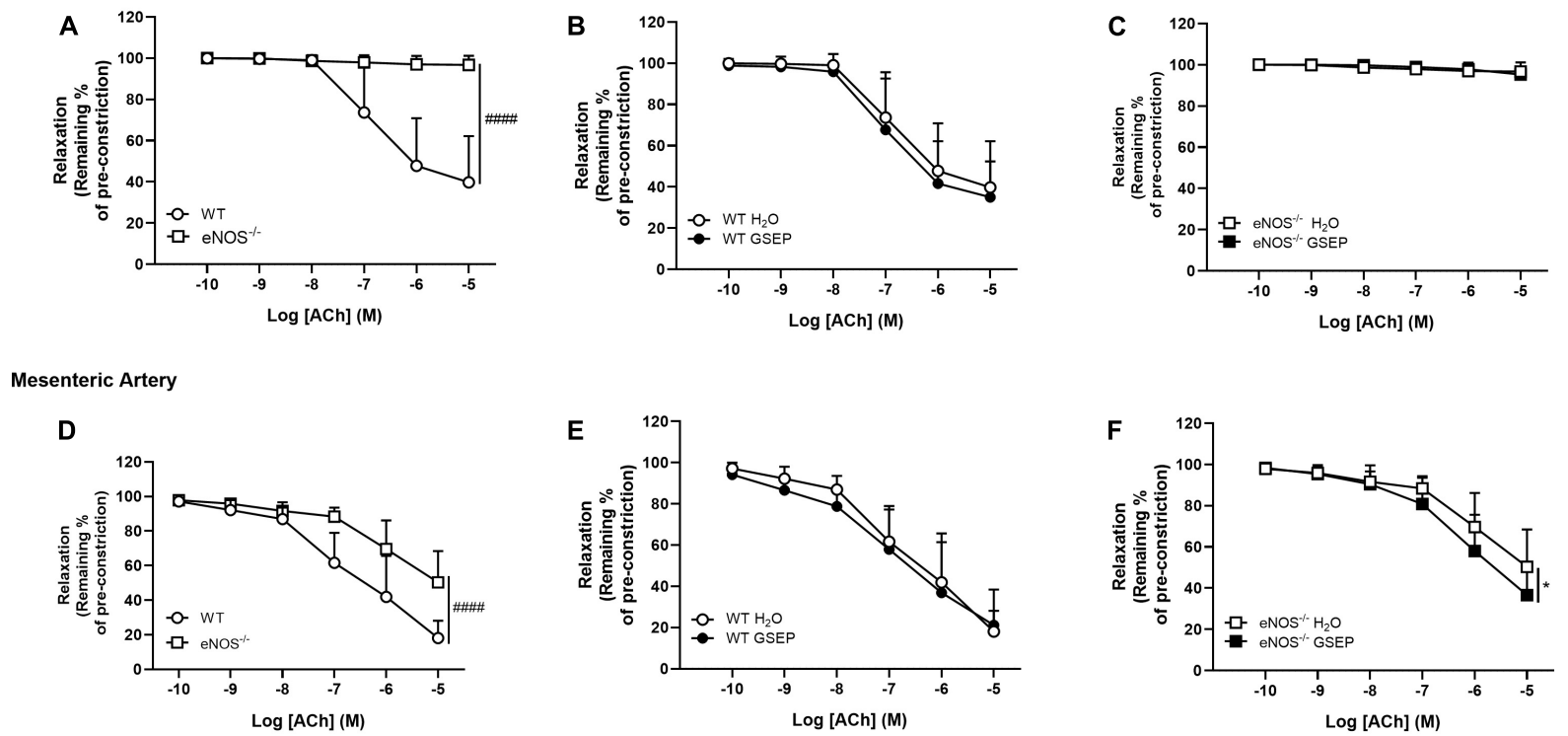

Uterine Artery
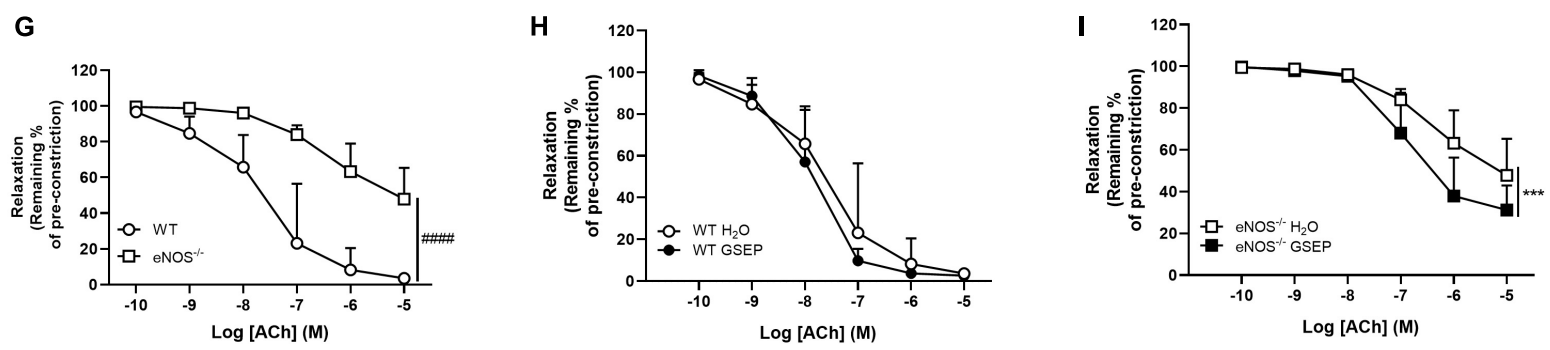

FIGURE 5 | GSEP supplementation improves endothelium-dependent relaxation of mesenteric and uterine arteries in eNOS ${ }^{-/-}$mice. In eNOS ${ }^{-/-}$mice, aortas did not relax in response to $\mathrm{ACh}(\mathbf{A}, \mathbf{C})$ and endothelium-dependent relaxation was significantly reduced in both mesenteric (D) and uterine (G) arteries compared with WT controls. Supplementation with GSEP had no effect on endothelium-dependent relaxation to ACh in aortas of WT mice (B). In both mesenteric and uterine arteries, relaxation to ACh was unaffected by GSEP in WT mice (E,H, respectively) but was significantly enhanced in eNOS ${ }^{-/-}$mice (F,I, respectively).

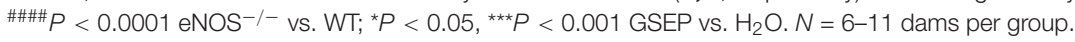

In low-income countries, where maternal hypertension remains highly prevalent, maternal and perinatal mortality are still a major concern (Noubiap et al., 2019), and adequate primary health care and prompt management of hypertension could significantly contribute to preventing the development of the most severe outcomes (Bagga et al., 2007).

To our knowledge, this is the first study investigating whether supplementation with GSEP, a widely available and highly bioactive compound, can improve vascular function in key target blood vessels in an established animal model of chronic hypertension in pregnancy.

The main finding of this study was that treatment with GSEP from mid-pregnancy may offer a broad protection of the maternal vasculature against hypertension and oxidative stress, by improving the function of resistance arteries and lowering SBP in pregnant $\mathrm{eNOS}^{-/-}$mice. The data substantially support our starting hypothesis and, importantly, these beneficial effects on maternal vascular function were not associated with any adverse fetal outcomes, suggesting this approach is safe.

Two clinical trials have already shown the potential for supplementation with GSEP to reduce blood pressure in nonpregnant patients with pre-hypertension (Park et al., 2016; Odai et al., 2019). In addition, a previous preclinical study investigated the effect of intragastric administration of GSEP in pregnancy, using the L-NAME-induced hypertensive mouse model. The authors measured SBP under anesthesia and demonstrated that treatment with GSEP reversed the hypertensive effect induced by L-NAME after 3 weeks of intervention (Zhu et al., 2018). In agreement with this finding, the current study showed a significant blood pressure-lowering effect of maternal supplementation with GSEP in pregnant $\mathrm{eNOS}^{-/-}$mice.

Unlike the L-NAME-induced hypertension model, eNOS ${ }^{-/-}$ mice display chronic hypertension (Shesely et al., 1996) and lower HR (Kulandavelu et al., 2006) compared with WT mice. The measurements of SBP at GD17.5 in $\mathrm{eNOS}^{-/-}$mice in 


\section{Aorta}
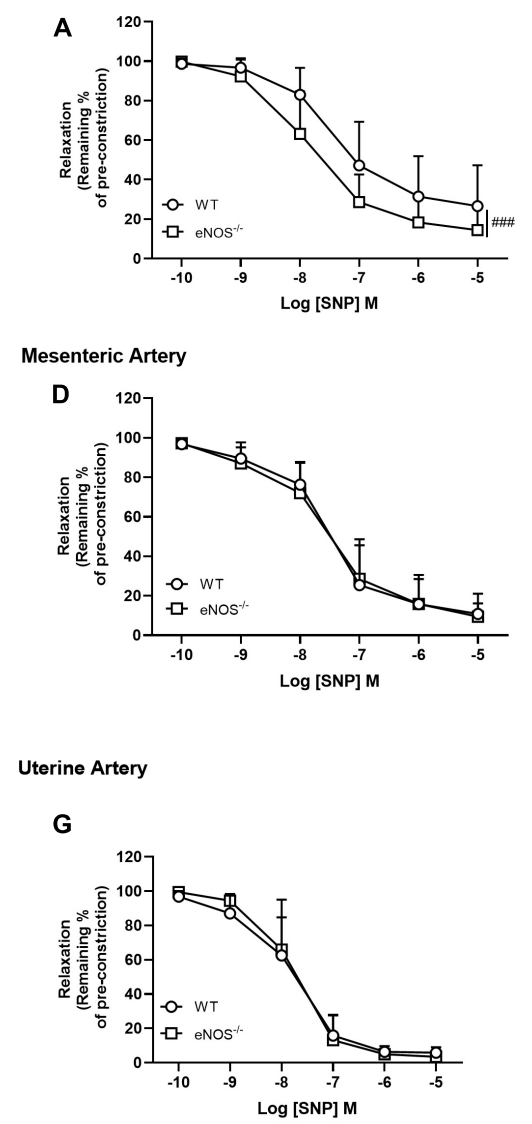
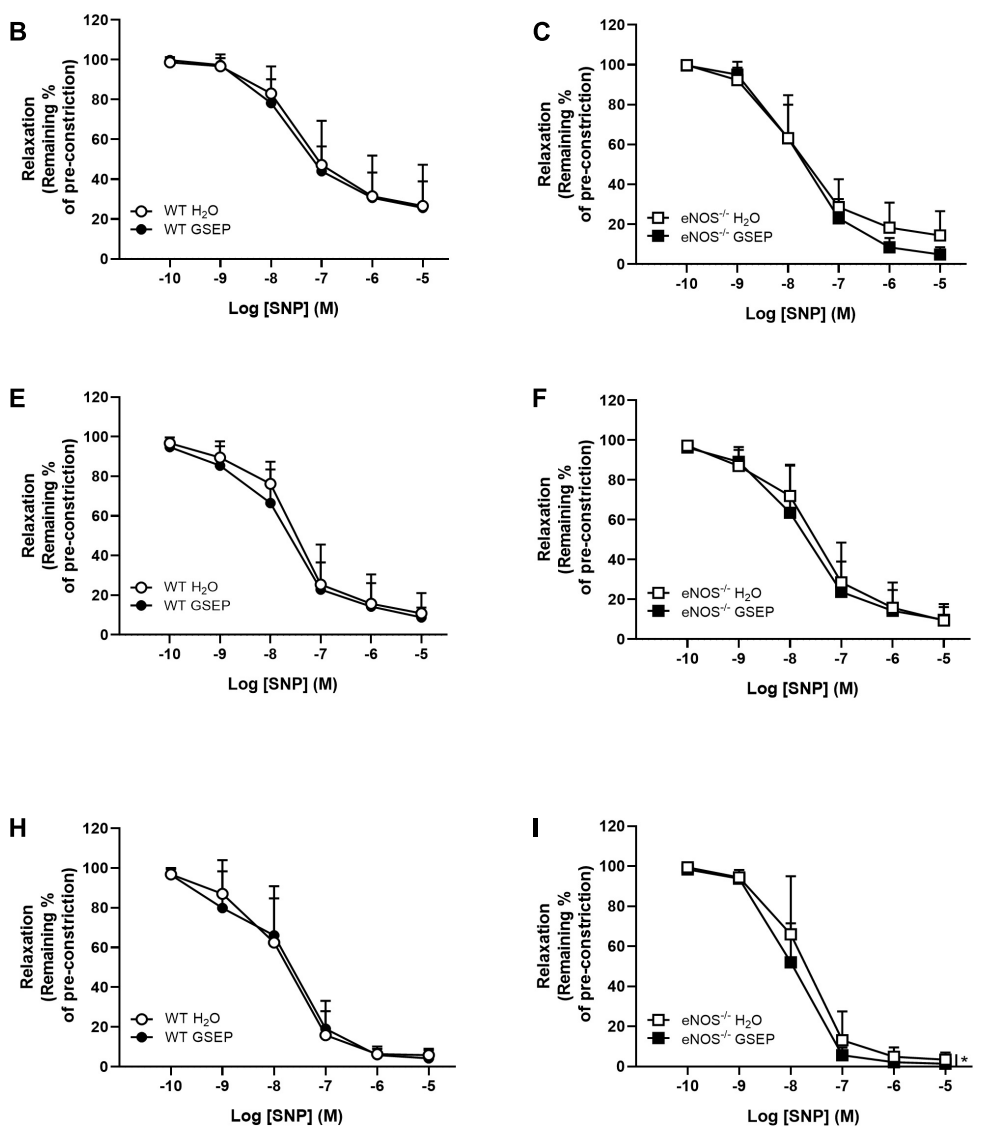

FIGURE 6 | Treatment with GSEP enhances endothelium-independent relaxation of uterine arteries in eNOS ${ }^{-/-}$mice. Endothelium-independent relaxation in response to SNP was significantly increased in aortas of eNOS ${ }^{-/-}$mice compared with WT controls (A), but did not change between genotypes in either mesenteric (D) or uterine arteries (G). Supplementation with GSEP had no effect on responses to SNP in either aortas (B,C) or mesenteric arteries (E,F) from WT and eNOS ${ }^{-/-}$ mice. In uterine arteries, the treatment had no effect in WT (H) but significantly improved relaxation to SNP in eNOS ${ }^{-/-}$mice (I). ${ }^{\# \# \# ~} P<0.001$ eNOS ${ }^{-/-}$vs. WT; ${ }^{\star} P<0.05$ GSEP vs. $\mathrm{H}_{2} \mathrm{O} . \mathrm{N}=6-11$ dams per group.

the current study are consistent with our own data (Tropea et al., 2020) and those reported by others (Hefler et al., 2001; Poudel et al., 2013). Administration of a different polyphenol, resveratrol (3,5, $4^{\prime}$-trihydroxystilbene), was reported to have no effect on SBP in $\mathrm{eNOS}^{-/}$mice (Poudel et al., 2013). In contrast, our recent data demonstrated that supplementation with beetroot juice significantly lowered SBP in eNOS - mice, effects which we believe are potentially attributable to bioactive phytochemicals contained within the juice, including polyphenols and flavonoids (Tropea et al., 2020), in common with the active constituents of GSEP. The phenolic content of the extract used in the current study has been reported to be $94 \%$ and mostly made of polymers of catechin (Edirisinghe et al., 2008; Sivaprakasapillai et al., 2009), shown to provide a higher antioxidant ability compared to other commonly used antioxidants (Bagchi et al., 1997, 1998). In vitro studies, have shown that GSEP are a better scavenger of free radicals, exhibiting 2-4 times more potent scavenging activity, than vitamin C and vitamin E (Bagchi et al., 1997). Similarly, in vivo studies have demonstrated that GSEP provide a greater protection against lipid peroxidation and DNA fragmentation compared with vitamin $\mathrm{C}$, vitamin $\mathrm{E}$ and $\beta$-carotene, in hepatic and brain tissues of the 12-O-tetradecanoylphorbol-13-acetate (TPA)induced oxidative damage mouse model (Bagchi et al., 1998).

Normal pregnancy is associated with oxidative stress (Chiarello et al., 2020), as increased ROS production plays a key role in signaling pathways that promote trophoblast invasion and placenta angiogenesis (Pereira et al., 2015). However, in addition to placental oxidative stress and impaired placental function (Myatt and Cui, 2004; Burton, 2009), an excessive production of ROS has been associated with the pathophysiology of many maternal hypertensive pregnancy-related complications, such as PE (Myatt and Cui, 2004; Burton and Jauniaux, 2011; Matsubara et al., 2015; Chiarello et al., 2020; San Juan-Reyes et al., 2020). In agreement with recently published data in the L-NAME mouse model (Zhu et al., 2018), we found that circulating concentrations of MDA were increased in the maternal plasma of $\mathrm{eNOS}^{-/}$mice compared with WT control groups, and that treatment with GSEP significantly reduced this marker of lipid peroxidation in the hypertensive strain. One significant 

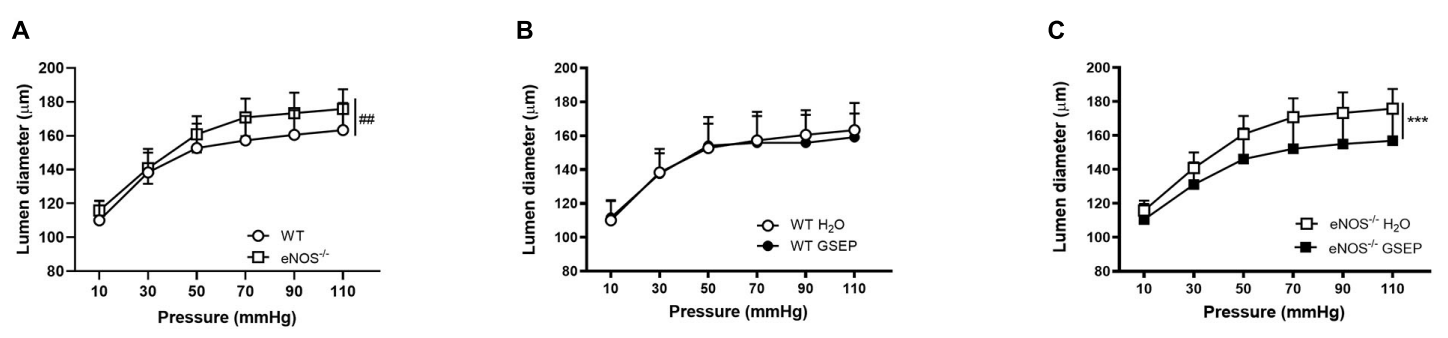

D

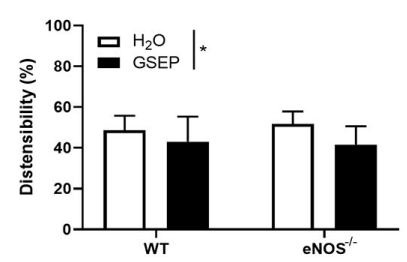

E

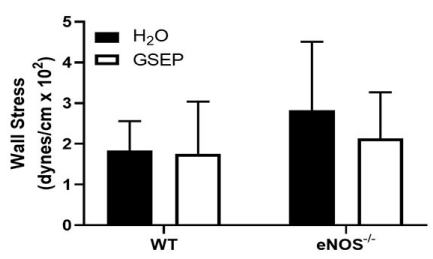

FIGURE 7 | Treatment with GSEP normalizes diameter of posterior cerebral arteries in eNOS ${ }^{-/-}$mice. Increasing intraluminal pressure (10-110 mmHg) significantly expanded lumen diameters of fully dilated posterior cerebral arteries of eNOS ${ }^{-1}$ mice compared with WT controls (A). Treatment with GSEP had no effect on lumen diameters of WT mice (B), but significantly reduced diameters in eNOS ${ }^{-/-}$mice (C). Distensibility (D) but not circumferential wall stress (E) at $110 \mathrm{mmHg}$ was significantly affected by the treatment. ${ }^{\# \#} P<0.01$ eNOS $^{-1-}$ vs. WT; ${ }^{*} P<0.05 ;{ }^{* \star *} P<0.001$ GSEP vs. $\mathrm{H}_{2} \mathrm{O} . \mathrm{N}=6-9$ dams per group.

TABLE 2 | Pregnancy outcomes.

\begin{tabular}{|c|c|c|c|c|c|c|c|}
\hline $\begin{array}{l}\text { Genotype } \\
\text { Treatment }\end{array}$ & \multicolumn{2}{|c|}{ WT } & \multicolumn{2}{|c|}{ eNOS ${ }^{-/-}$} & \multicolumn{3}{|c|}{ Effects } \\
\hline Fetal weight (g) & $1.14 \pm 0.05$ & $1.14 \pm 0.05$ & $0.95 \pm 0.09$ & $0.99 \pm 0.07$ & NS & \#\#\#\# & NS \\
\hline Placental weight (mg) & $80.6 \pm 3.9$ & $80.4 \pm 4.2$ & $80.9 \pm 6.9$ & $81.3 \pm 4.9$ & NS & NS & NS \\
\hline Litter size (fetuses/dam) & $8.0(5.0-11.0)$ & $8.0(1.0-10.0)$ & $8.0(5.0-9.0)$ & $7.0(4.0-9.0)$ & NS & NS & NS \\
\hline Resorptions (number/itter) & $2.0(0.0-3.0)$ & $1.0(0.0-4.0)$ & $0.5(0.0-2.0)$ & $0.5(0.0-3.0)$ & NS & $P=0.0651$ & NS \\
\hline
\end{tabular}

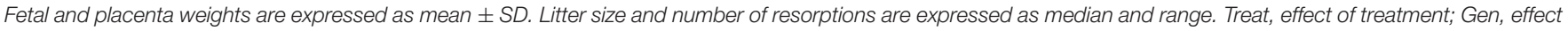
of genotype; Int, interaction between genotype and treatment. \#\#\#\# $P<0.0001$ WT vs. eNOS ${ }^{-1-}$; NS, not significant. N = 6-11 dams per group.

limitation of this study is mouse plasma volume availability, as investigation of several relevant biomarkers in addition to MDA, are needed to address a complete evaluation of oxidative stress in both maternal and fetal samples.

MDA is a major metabolite of lipid peroxide breakdown and one of the first biomarkers of oxidative stress found in the maternal circulation of women with PE (Myatt and Cui, 2004; Kaur et al., 2008; Poston et al., 2011; Haram et al., 2019). Thus, the similarities of findings in hypertensive animal models, such as those used in the present study, with those described in pregnant women (Myatt and Cui, 2004; Kaur et al., 2008; Poston et al., 2011) support the use of these animal models in translational pregnancy research.

There is still very little convincing evidence that supplementation with known antioxidants can elicit potential benefit in pregnant women with a range of clinical risk factors. Despite promising effects in a pilot trial (Chappell et al., 2002), subsequent studies evaluating the effect of supplementation with vitamins $\mathrm{C}$ and $\mathrm{E}$ in women at high-risk of developing PE not only failed to prevent the disease (Poston et al., 2006), but importantly, revealed increased rate of low-birthweight babies in the treatment arm of the study, thus precluding the use of this particular antioxidant strategy in pregnancy (Poston et al., 2006). Of note, pro-oxidant activity of vitamins $\mathrm{C}$ and E has been demonstrated at high doses (Pearson et al., 2006; Varadharaj et al., 2006), emphasizing the importance of dose selection when considering any antioxidant strategy. However, a wide variety of dietary sources of natural antioxidants, including polyphenols, is underexplored and investigation of their effects in pregnancy is currently a key research area. A recent randomized controlled pilot study has shown potential neuroprotective effects of maternal pomegranate juice supplementation, which is also rich in antioxidants and bioactive polyphenols, in FGR newborns at risk for hypoxic-ischemic injury (Matthews et al., 2019). A double-blind randomized controlled trial using EGCG as an intervention in pregnant women with gestational diabetes mellitus, reported therapeutic effects of this natural catechin-rich compound for both maternal and neonatal complications, such as improved low-birthweight and lower number of infants with hypoglycemia (Zhang et al., 2017). Similarly, cardioprotective effects against doxorubicin-mediated myocyte dysfunction were seen in cardiomyocytes of neonatal 
rats following catechin-rich polyphenolic supplementation (Li et al., 2010).

A growing body of evidence from clinical trials has shown beneficial effects of supplementation with GSEP to reduce oxidized LDL, aiming to lower the risk of cardiovascular disorders in non-pregnant patients (Preuss et al., 2000; Sano et al., 2007; Razavi et al., 2013), and supplementation with GSEP has been demonstrated to reduce brain lipid peroxidation and provide neuroprotection in newborns from a rat hypoxiaischemic brain injury model (Feng et al., 2005). To the best of our knowledge, there is no report of low birthweight or developmental toxic effects following maternal supplementation with GSEP (Zhu et al., 2018; Althali et al., 2019) or high levels of catechin in animal models (Lesser et al., 2015).

Fetuses of $\mathrm{eNOS}^{-/-}$dams display a $\sim 10 \%$ lower weight than those of WT and exhibit an FGR phenotype (Kusinski et al., 2012). Several treatment options have been investigated to test the potential therapeutic effect of polyphenols and other antioxidants during pregnancy in this mouse model, showing conflicting results on fetal outcomes. In a recently published work (Finn-Sell et al., 2018), maternal supplementation with pomegranate juice had detrimental effects on fetal outcomes of both WT and $\mathrm{eNOS}^{-/-}$mice; whereas, treatment with resveratrol showed a trend toward an increase in fetal weight in eNOS $^{-/-}$mice (Poudel et al., 2013) and the antioxidant drug Tempol (4-Hydroxy-2,2,6,6-tetramethylpiperidin-1-oxyl) improved fetal growth in eNOS ${ }^{-/-}$mice (Stanley et al., 2012). More recently, maternal supplementation with either melatonin (Renshall et al., 2018), or with beetroot juice (Tropea et al., 2020), had no effects on NOS $^{-/-}$fetuses. In agreement with the latter data, our results showed that GSEP did not improve fetal growth in fetuses from $\mathrm{eNOS}^{-/}$dams. It appears that therapeutic interventions mostly fail to improve fetal outcomes in eNOS $^{-/-}$mice. The growth potential of this homozygous knockout mouse as a model of FGR may be genetically limited (Tropea et al., 2020), thus representing a key limitation for studies in which intervention aim at ameliorating the FGR phenotype.

However, there was no detrimental effect on the growth of fetuses in WT mice or any further reduction in fetal growth in eNOS $^{-/-}$mice. Further studies investigating the effect of these substances on postnatal growth and development in the offspring are warranted before translating potentially safe interventions into strategies for pregnant women.

\section{Effects of GSEP Predominate in Resistance Arteries of the Pregnant eNOS $^{-/-}$Mouse}

Mammalian pregnancy requires physiological vascular adaptations to accommodate for the progressive increase in blood volume, while preventing the development of maternal hypertension (Osol et al., 2019). The endogenous vasodilator NO increases blood flow and regulates vascular smooth muscle tone (Moncada and Higgs, 2006) in the uterine and systemic circulation by balancing the release of both endogenous vasodilators and vasoconstrictors (Tanbe and Khalil, 2010). To investigate the potential for GSEP to alter vascular function, we explored effects of this treatment on the vascular tone of pharmacologically stimulated conduit (aorta), systemic (mesenteric) and reproductive (uterine) arteries. In agreement with previous findings in non-pregnant $\mathrm{NNOS}^{-/-}$ mice (Chataigneau et al., 1999; Waldron et al., 1999; Brandes et al., 2000; Lamping and Faraci, 2003), vasoconstriction and endothelium-independent relaxation were both significantly enhanced in aortas of $\mathrm{NOOS}^{-/}$compared with WT mice, whereas there was a complete absence of endotheliumdependent relaxation in these arteries. Contrary to the previous study by Zhu et al. (2018), where maternal administration of GSEP enhanced endothelium-dependent relaxation in aortas of a non-genetic model of hypertension, we did not demonstrate a similar effect of GSEP in this vascular bed.

The present study is the first to assess the effects of GSEP supplementation on resistance-sized blood vessels and demonstrates stark vascular bed differences between conduit and resistance arteries. Contrary to effects on the aorta, supplementation with GSEP significantly improved endothelium-dependent relaxation in both mesenteric and uterine arteries of $\mathrm{eNOS}^{-/-}$mice.

The endothelium-dependent relaxing activity of GSEP exhibited in vitro in rat aortic rings has been reported to increase with the degree of proanthocyanidin polymerization (Fitzpatrick et al., 2000, 2002), and interestingly, a structure-activity relationship has been hypothesized to stimulate a pseudo laminar shear stress response in endothelial cells, through which GSEP is thought to modify vascular function (Corder et al., 2004). This new concept could suggest a pathway through which GSEP may affect the function of blood vessels.

As well as highlighting differences between conduit and resistance arteries in terms of effects of GSEP to enhance endothelium-dependent vasorelaxation, our data also illustrated that supplementation with GSEP significantly increased U46619induced constriction in uterine arteries. As already reported for other vasoconstricting agents (D'Angelo and Osol, 1993), the higher sensitivity of uterine compared with mesenteric arteries for U46619 in eNOS ${ }^{-/-}$mice (data not shown), reflects regional differences of the maternal vasculature to adapt to pregnancy (D’Angelo and Osol, 1993; Osol et al., 2019). Unlike in the uterine arteries, we observed the opposite trend in mesenteric arteries of eNOS ${ }^{-/-}$mice treated with GSEP, which may underlie the SBP-lowering effect mediated by the extract in the systemic vasculature of the hypertensive strain.

The exact mechanisms through which GSEP affects these vascular beds are currently unknown, which reflects a limitation in studies investigating vascular effects of bioactive compounds through underexplored nutritional interventions. Although beyond the scope of this study, future work will focus on determining molecular pathways activated by GSEP during pregnancy.

\section{Effects of GSEP May Protect the Maternal Cerebral Microvasculature}

Despite substantial hemodynamic changes in almost every other vascular bed, the adaptation of the cerebrovasculature 
to pregnancy maintains normal vascular resistance and blood flow, such that there are negligible effects on cerebral blood flow during pregnancy (Johnson and Cipolla, 2015). Impaired endothelial function and hypertension underpin the increased risk of maternal intracerebral hemorrhage in pregnant women (Shawwa et al., 2018). Under normal conditions, cerebral endothelial cells composing the blood-brain barrier provide protection from harm (Obermeier et al., 2013); however, chronic elevation of intraluminal arterial pressure can weaken the vessel wall and cause microvascular damage (Fisher, 1971). Hypertension is the most common cause of intracerebral hemorrhage (Keep et al., 2014). Indeed, as a result of the substantial increase in pressure-induced forced vasodilatation, cerebral arterioles can burst, causing intracerebral hemorrhage and blood-brain barrier disruption (Johansson et al., 1970; Keep et al., 2014).

Although rare in developed countries, intracerebral hemorrhage remains the main final cause of maternal death in hypertensive disorders of pregnancy (Ascanio et al., 2019; Conti-Ramsden et al., 2019), with the greatest incidence in the third trimester and in the puerperium (Bateman et al., 2006; Davie and O'Brien, 2008). Simulating an increase in intraluminal pressure in posterior cerebral arteries, we have shown that lumen diameter is significantly increased in arterioles of $\mathrm{NOS}^{-/-}$mice compared with those of the WT, suggesting impaired cerebral vasoregulation in this hypertensive model. Treatment with GSEP showed no effect on posterior cerebral arteries of WT mice, but in vessels from $\mathrm{eNOS}^{-/}$mice, significantly reduced lumen diameters under conditions of high intraluminal pressure. This effect of GSEP on posterior cerebral arteries could decrease transmission of pressure in the downstream microcirculation and potentially provide a protective mechanism from forced vasodilatation, by which to preserve blood brain barrier integrity. The lack of effect in WT animals suggests the safety of this intervention in pregnancy also in the cerebral vasculature. The ability of GSEP to normalize lumen diameters of posterior cerebral arteries, in addition to the positive effects on the systemic resistance arteries outlined above, is suggestive of the potential broad spectrum of protective effects of this intervention, at least in the eNOS ${ }^{-/-}$ mouse model. It is possible that the effects seen in this vascular bed are a direct consequence of the GSEP blood pressurelowering properties and associated improved systemic vascular function. However, others have demonstrated alterations in extracellular matrix biological structure and function of the arterial wall in response to GSEP treatment (Ivanov et al., 2007; De Bruyne et al., 2019), which may also play a role in the $\mathrm{eNOS}^{-/-}$mouse.

Taken together, our data indicate that maternal supplementation with GSEP could offer a cheap and widely available treatment to improve maternal vascular health in hypertensive pregnancies. Protective effects of GSEP against vascular dysfunction have been attributed to their antioxidant properties (Wang et al., 2010; Okudan et al., 2011; Pinna et al., 2017; Zhu et al., 2018; Sato et al., 2020). Furthermore, the treatment did not have adverse effects on fetal outcome and the potential for GSEP as a therapy for complications of chronic hypertension in pregnancy is worthy of further research.

\section{CONCLUSION}

In conclusion, this study reports that maternal administration of GSEP during pregnancy leads to a reduction in SBP in eNOS ${ }^{-/-}$ mice, which may be mediated by the antioxidant potential of the extract to improve systemic vascular function. In addition, the effect of GSEP supplementation on cerebral arterioles indicates that GSEP may protect vascular integrity of the downstream cerebral microcirculation in the brain. The current findings warrant further investigation and require the development of preclinical models exhibiting intracerebral hemorrhage in pregnancy in which to test this intervention. Collectively, our data substantiate supplementation with GSEP as a promising treatment in pregnancies complicated by maternal hypertension. Delineating the pathways and molecular mechanisms involved in these beneficial effects will require further investigation.

\section{DATA AVAILABILITY STATEMENT}

The raw data supporting the conclusions of this article will be made available by the authors, without undue reservation, to any qualified researcher.

\section{ETHICS STATEMENT}

The animal study was reviewed and approved by the Local Animal Welfare and Ethical Review Board of the University of Manchester.

\section{AUTHOR CONTRIBUTIONS}

TT conceived and designed the study, performed the research, and wrote the manuscript. SLG, CPS, and ECC contributed to the conception and design of the study and critically revised the manuscript for important intellectual content. All authors contributed to the article and approved the submitted version.

\section{FUNDING}

TT and ECC were funded by a BHF Intermediate Fellowship to ECC.

\section{ACKNOWLEDGMENTS}

We would like to thank the staff of the Biological Services Facility at the University of Manchester, particularly Renata Orzechowska, for care of the experimental animals used in this project. We wanted to give a special thanks to Professor Marilyn Cipolla, University of Vermont, United States, for providing advice with her expertise on the cerebrovasculature. Polyphenolics, Madera, CA, kindly provided GSEP. 


\section{REFERENCES}

Albrecht, E. W., Stegeman, C. A., Heeringa, P., Henning, R. H., and van Goor, H. (2003). Protective role of endothelial nitric oxide synthase. J. Pathol. 199, 8-17. doi: $10.1002 /$ path. 1250

Althali, N. J., Hassan, A. M., and Abdel-Wahhab, M. A. (2019). Effect of grape seed extract on maternal toxicity and in utero development in mice treated with zearalenone. Environ. Sci. Pollut. Res. Int. 26, 5990-5999. doi: 10.1007/s11356018-4011-x

Ascanio, L. C., Maragkos, G. A., Young, B. C., Boone, M. D., and Kasper, E. M. (2019). Spontaneous intracranial hemorrhage in pregnancy: a systematic review of the literature. Neurocrit. Care 30, 5-15. doi: 10.1007/s12028-018-0501-4

Bagchi, D., Bagchi, M., Stohs, S. J., Das, D. K., Ray, S. D., Kuszynski, C. A., et al. (2000). Free radicals and grape seed proanthocyanidin extract: importance in human health and disease prevention. Toxicology 148, 187-197. doi: 10.1016/ s0300-483x(00)00210-9

Bagchi, D., Garg, A., Krohn, R. L., Bagchi, M., Bagchi, D. J., Balmoori, J., et al. (1998). Protective effects of grape seed proanthocyanidins and selected antioxidants against TPA-induced hepatic and brain lipid peroxidation and DNA fragmentation, and peritoneal macrophage activation in mice. Gen. Pharmacol. 30, 771-776. doi: 10.1016/s0306-3623(97)00332-7

Bagchi, D., Garg, A., Krohn, R. L., Bagchi, M., Tran, M. X., and Stohs, S. J. (1997). Oxygen free radical scavenging abilities of vitamins $\mathrm{C}$ and $\mathrm{E}$, and a grape seed proanthocyanidin extract in vitro. Res. Commun. Mol. Pathol. Pharmacol. 95, 179-189.

Bagga, R., Aggarwal, N., Chopra, V., Saha, S. C., Prasad, G. R., and Dhaliwal, L. K. (2007). Pregnancy complicated by severe chronic hypertension: a 10year analysis from a developing country. Hypertens. Pregnancy 26, 139-149. doi: 10.1080/10641950701204588

Bateman, B. T., Schumacher, H. C., Bushnell, C. D., Pile-Spellman, J., Simpson, L. L., Sacco, R. L., et al. (2006). Intracerebral hemorrhage in pregnancy: frequency, risk factors, and outcome. Neurology 67, 424-429. doi: 10.1212/01. wnl.0000228277.84760.a2

Bellamy, L., Casas, J. P., Hingorani, A. D., and Williams, D. J. (2007). Pre-eclampsia and risk of cardiovascular disease and cancer in later life: systematic review and meta-analysis. BMJ 335:974. doi: 10.1136/bmj.39335.385301.BE

Bramham, K., Parnell, B., Nelson-Piercy, C., Seed, P. T., Poston, L., and Chappell, L. C. (2014). Chronic hypertension and pregnancy outcomes: systematic review and meta-analysis. BMJ 348:g2301. doi: 10.1136/bmj.g2301

Brandes, R. P., Kim, D., Schmitz-Winnenthal, F. H., Amidi, M., Gödecke, A., Mülsch, A., et al. (2000). Increased nitrovasodilator sensitivity in endothelial nitric oxide synthase knockout mice: role of soluble guanylyl cyclase. Hypertension 35(1 Pt 2), 231-236. doi: 10.1161/01.hyp.35.1.231

Burton, G. J. (2009). Oxygen, the Janus gas; its effects on human placental development and function. J. Anat. 215, 27-35. doi: 10.1111/j.1469-7580.2008. 00978.x

Burton, G. J., and Jauniaux, E. (2011). Oxidative stress. Best Pract. Res. Clin. Obstet. Gynaecol. 25, 287-299. doi: 10.1016/j.bpobgyn.2010.10.016

Chappell, L. C., Enye, S., Seed, P., Briley, A. L., Poston, L., and Shennan, A. H. (2008). Adverse perinatal outcomes and risk factors for preeclampsia in women with chronic hypertension: a prospective study. Hypertension 51, 1002-1009. doi: 10.1161/HYPERTENSIONAHA.107.107565

Chappell, L. C., Seed, P. T., Kelly, F. J., Briley, A., Hunt, B. J., Charnock-Jones, D. S., et al. (2002). Vitamin C and E supplementation in women at risk of preeclampsia is associated with changes in indices of oxidative stress and placental function. Am. J. Obstet. Gynecol. 187, 777-784. doi: 10.1067/mob. 2002.125735

Chataigneau, T., Félétou, M., Huang, P. L., Fishman, M. C., Duhault, J., and Vanhoutte, P. M. (1999). Acetylcholine-induced relaxation in blood vessels from endothelial nitric oxide synthase knockout mice. Br. J. Pharmacol. 126, 219-226. doi: 10.1038/sj.bjp.0702300

Chiarello, D. I., Abad, C., Rojas, D., Toledo, F., Vázquez, C. M., Mate, A., et al. (2020). Oxidative stress: normal pregnancy versus preeclampsia. Biochim. Biophys. Acta Mol. Basis Dis. 1866:165354. doi: 10.1016/j.bbadis.2018.12.005

Cipolla, M. J., DeLance, N., and Vitullo, L. (2006). Pregnancy prevents hypertensive remodeling of cerebral arteries: a potential role in the development of eclampsia. Hypertension 47, 619-626. doi: 10.1161/01.HYP.0000196948. 15019.28
Conti-Ramsden, F., Knight, M., Green, M., Shennan, A. H., and Chappell, L. C. (2019). Reducing maternal deaths from hypertensive disorders: learning from confidential inquiries. BMJ 364:1230. doi: 10.1136/bmj.1230

Corder, R., Warburton, R. C., Khan, N. Q., Brown, R. E., Wood, E. G., and Lees, D. M. (2004). The procyanidin-induced pseudo laminar shear stress response: a new concept for the reversal of endothelial dysfunction. Clin. Sci. 107, 513-517. doi: 10.1042/CS20040189

D’Angelo, G., and Osol, G. (1993). Regional variation in resistance artery diameter responses to alpha-adrenergic stimulation during pregnancy. Am. J. Physiol. 264(1 Pt 2), H78-H85. doi: 10.1152/ajpheart.1993.264. 1.H78

Davie, C. A., and O'Brien, P. (2008). Stroke and pregnancy. J. Neurol. Neurosurg. Psychiatry 79, 240-245. doi: 10.1136/jnnp.2007.116939

De Bruyne, T., Steenput, B., Roth, L., De Meyer, G. R. Y., Santos, C. N. D., Valentová, K., et al. (2019). Dietary polyphenols targeting arterial stiffness: interplay of contributing mechanisms and gut microbiome-related metabolism. Nutrients 11:578. doi: 10.3390/nu11030578

Edirisinghe, I., Burton-Freeman, B., and Tissa Kappagoda, C. (2008). Mechanism of the endothelium-dependent relaxation evoked by a grape seed extract. Clin. Sci. 114, 331-337. doi: 10.1042/CS20070264

Feng, Y., Liu, Y. M., Fratkins, J. D., and LeBlanc, M. H. (2005). Grape seed extract suppresses lipid peroxidation and reduces hypoxic ischemic brain injury in neonatal rats. Brain Res. Bull. 66, 120-127. doi: 10.1016/j.brainresbull.2005. 04.006

Finn-Sell, S. L., Cottrell, E. C., Greenwood, S. L., Dilworth, M. R., Cowley, E. J., Sibley, C. P., et al. (2018). Pomegranate juice supplementation alters uteroplacental vascular function and fetal growth in the eNOS. Front. Physiol. 9:1145. doi: 10.3389/fphys.2018.01145

Fisher, C. M. (1971). Pathological observations in hypertensive cerebral hemorrhage. J. Neuropathol. Exp. Neurol. 30, 536-550. doi: 10.1097/00005072197107000-00015

Fitzpatrick, D. F., Bing, B., Maggi, D. A., Fleming, R. C., and O’Malley, R. M. (2002). Vasodilating procyanidins derived from grape seeds. Ann. N. Y. Acad. Sci. 957, 78-89. doi: 10.1111/j.1749-6632.2002.tb02907.x

Fitzpatrick, D. F., Fleming, R. C., Bing, B., Maggi, D. A., and O’Malley, R. M. (2000). Isolation and characterization of endothelium-dependent vasorelaxing compounds from grape seeds. J. Agric. Food Chem. 48, 6384-6390. doi: 10.1021/ jf0009347

Gilbert, W. M., Young, A. L., and Danielsen, B. (2007). Pregnancy outcomes in women with chronic hypertension: a population-based study. J. Reprod. Med. 52, 1046-1051.

Haddad, B., and Sibai, B. M. (1999). Chronic hypertension in pregnancy. Ann. Med. 31, 246-252. doi: 10.3109/07853899908995887

Haram, K., Mortensen, J. H., Myking, O., Magann, E. F., and Morrison, J. C. (2019). The role of oxidative stress, adhesion molecules and antioxidants in preeclampsia. Curr. Hypertens. Rev. 15, 105-112. doi: 10.2174/ 1573402115666190119163942

Hefler, L. A., Tempfer, C. B., Moreno, R. M., O’Brien, W. E., and Gregg, A. R. (2001). Endothelial-derived nitric oxide and angiotensinogen: blood pressure and metabolism during mouse pregnancy. Am. J. Physiol. Regul. Integr. Comp. Physiol. 280, R174-R182. doi: 10.1152/ajpregu.2001.280. 1.R174

Ivanov, V., Ivanova, S., Roomi, M. W., Kalinovsky, T., Niedzwiecki, A., and Rath, M. (2007). Extracellular matrix-mediated control of aortic smooth muscle cell growth and migration by a combination of ascorbic acid, lysine, proline, and catechins. J. Cardiovasc. Pharmacol. 50, 541-547. doi: 10.1097/FJC. 0b013e318145148e

Jain, L. (1997). Effect of pregnancy-induced and chronic hypertension on pregnancy outcome. J. Perinatol. 17, 425-427.

Johansson, B., Li, C. L., Olsson, Y., and Klatzo, I. (1970). The effect of acute arterial hypertension on the blood-brain barrier to protein tracers. Acta Neuropathol. 16, 117-124. doi: 10.1007/BF00687666

Johnson, A. C., and Cipolla, M. J. (2015). The cerebral circulation during pregnancy: adapting to preserve normalcy. Physiology 30, 139-147. doi: 10. 1152/physiol.00048.2014

Kaur, G., Mishra, S., Sehgal, A., and Prasad, R. (2008). Alterations in lipid peroxidation and antioxidant status in pregnancy with preeclampsia. Mol. Cell Biochem. 313, 37-44. doi: 10.1007/s11010-008-9739-z 
Keep, R. F., Zhou, N., Xiang, J., Andjelkovic, A. V., Hua, Y., and Xi, G. (2014). Vascular disruption and blood-brain barrier dysfunction in intracerebral hemorrhage. Fluids Barriers CNS 11:18. doi: 10.1186/2045-8118-11-18

Kulandavelu, S., Qu, D., and Adamson, S. L. (2006). Cardiovascular function in mice during normal pregnancy and in the absence of endothelial NO synthase. Hypertension 47, 1175-1182. doi: 10.1161/01.HYP.0000218440.71846.db

Kusinski, L. C., Stanley, J. L., Dilworth, M. R., Hirt, C. J., Andersson, I. J., Renshall, L. J., et al. (2012). eNOS knockout mouse as a model of fetal growth restriction with an impaired uterine artery function and placental transport phenotype. Am. J. Physiol. Regul. Integr. Comp. Physiol. 303, R86-R93. doi: 10.1152/ajpregu. 00600.2011

Lamping, K., and Faraci, F. (2003). Enhanced vasoconstrictor responses in eNOS deficient mice. Nitric Oxide 8, 207-213. doi: 10.1016/s1089-8603(03)00028-4

Landmesser, U., Hornig, B., and Drexler, H. (2004). Endothelial function: a critical determinant in atherosclerosis? Circulation 109(21 Suppl. 1), II27-II33. doi: 10.1161/01.CIR.0000129501.88485.1f

Lesser, M. N. R., Keen, C. L., and Lanoue, L. (2015). Reproductive and developmental outcomes, and influence on maternal and offspring tissue mineral concentrations, of (-)-epicatechin, (+)-catechin, and rutin ingestion prior to, and during pregnancy and lactation in C57BL/6J mice. Toxicol. Rep. 2, 443-449. doi: 10.1016/j.toxrep.2015.01.003

Li, W., Nie, S., Xie, M., Chen, Y., Li, C., and Zhang, H. (2010). A major green tea component, (-)-epigallocatechin-3-gallate, ameliorates doxorubicin-mediated cardiotoxicity in cardiomyocytes of neonatal rats. J. Agric. Food Chem. 58, 8977-8982. doi: $10.1021 / \mathrm{jf} 101277 \mathrm{t}$

Livingston, J. C., and Sibai, B. M. (2001). Chronic hypertension in pregnancy. Obstet. Gynecol. Clin. North Am. 28, 447-463. doi: 10.1016/s0889-8545(05) 70213-8

Lum, H., and Roebuck, K. A. (2001). Oxidant stress and endothelial cell dysfunction. Am. J. Physiol. Cell Physiol. 280, C719-C741. doi: 10.1152/ajpcell. 2001.280.4.C719

Maducolil, M. K., Al-Obaidly, S., Olukade, T., Salama, H., AlQubaisi, M., and Al Rifai, H. (2020). Maternal characteristics and pregnancy outcomes of women with chronic hypertension: a population-based study. J. Perinat. Med. 48, 139-143. doi: 10.1515/jpm-2019-0293

Matsubara, K., Higaki, T., Matsubara, Y., and Nawa, A. (2015). Nitric oxide and reactive oxygen species in the pathogenesis of preeclampsia. Int. J. Mol. Sci. 16, 4600-4614. doi: 10.3390/ijms16034600

Matthews, L. G., Smyser, C. D., Cherkerzian, S., Alexopoulos, D., Kenley, J., Tuuli, M. G., et al. (2019). Maternal pomegranate juice intake and brain structure and function in infants with intrauterine growth restriction: a randomized controlled pilot study. PLoS One 14:e0219596. doi: 10.1371/journal.pone. 0219596

Miranda Guisado, M. L., Vallejo-Vaz, A. J., García Junco, P. S., Jiménez Jiménez, L., García Morillo, S., Muñiz Grijalvo, O., et al. (2012). Abnormal levels of antioxidant defenses in a large sample of patients with hypertensive disorders of pregnancy. Hypertens. Res. 35, 274-278. doi: 10.1038/hr.2011.200

Moncada, S., and Higgs, E. A. (2006). The discovery of nitric oxide and its role in vascular biology. Br. J. Pharmacol. 147(Suppl. 1), S193-S201. doi: 10.1038/sj. bjp.0706458

Moodley, J. (2008). Maternal deaths due to hypertensive disorders in pregnancy. Best Pract. Res. Clin. Obstet. Gynaecol. 22, 559-567. doi: 10.1016/j.bpobgyn. 2007.11.004

Mulvany, M. J., and Halpern, W. (1977). Contractile properties of small arterial resistance vessels in spontaneously hypertensive and normotensive rats. Circ. Res. 41, 19-26. doi: 10.1161/01.res.41.1.19

Myatt, L. (2010). Review: reactive oxygen and nitrogen species and functional adaptation of the placenta. Placenta 31, S66-S69. doi: 10.1016/j.placenta.2009. 12.021

Myatt, L., and Cui, X. (2004). Oxidative stress in the placenta. Histochem. Cell Biol. 122, 369-382. doi: 10.1007/s00418-004-0677-x

Noubiap, J. J., Bigna, J. J., Nyaga, U. F., Jingi, A. M., Kaze, A. D., Nansseu, J. R., et al. (2019). The burden of hypertensive disorders of pregnancy in Africa: a systematic review and meta-analysis. J. Clin. Hypertens. 21, 479-488. doi: $10.1111 /$ jch. 13514

Obermeier, B., Daneman, R., and Ransohoff, R. M. (2013). Development, maintenance and disruption of the blood-brain barrier. Nat Med 19, 1584-1596. doi: $10.1038 / \mathrm{nm} .3407$
Odai, T., Terauchi, M., Kato, K., Hirose, A., and Miyasaka, N. (2019). Effects of grape seed proanthocyanidin extract on vascular endothelial function in participants with prehypertension: a randomized, double-blind, placebocontrolled study. Nutrients 11:2844. doi: 10.3390/nu11122844

Okudan, N., Barışkaner, H., Gökbel, H., Sahin, A. S., Belviranll, M., and Baysal, H. (2011). The effect of supplementation of grape seed proanthocyanidin extract on vascular dysfunction in experimental diabetes. J. Med. Food 14, 1298-1302. doi: 10.1089/jmf.2010.0030

Osol, G., Ko, N. L., and Mandalà, M. (2019). Plasticity of the maternal vasculature during pregnancy. Annu. Rev. Physiol. 81, 89-111. doi: 10.1146/annurevphysiol-020518-114435

Oueslati, N., Charradi, K., Bedhiafi, T., Limam, F., and Aouani, E. (2016). Protective effect of grape seed and skin extract against diabetes-induced oxidative stress and renal dysfunction in virgin and pregnant rat. Biomed. Pharmacother. 83, 584-592. doi: 10.1016/j.biopha.2016.07.024

Park, E., Edirisinghe, I., Choy, Y. Y., Waterhouse, A., and Burton-Freeman, B. (2016). Effects of grape seed extract beverage on blood pressure and metabolic indices in individuals with pre-hypertension: a randomised, double-blinded, two-arm, parallel, placebo-controlled trial. Br. J. Nutr. 115, 226-238. doi: 10. 1017/S0007114515004328

Pearson, P., Lewis, S. A., Britton, J., Young, I. S., and Fogarty, A. (2006). The pro-oxidant activity of high-dose vitamin E supplements in vivo. BioDrugs 20, 271-273. doi: 10.2165/00063030-200620050-00002

Pereira, R. D., De Long, N. E., Wang, R. C., Yazdi, F. T., Holloway, A. C., and Raha, S. (2015). Angiogenesis in the placenta: the role of reactive oxygen species signaling. Biomed. Res. Int. 2015:814543. doi: 10.1155/2015/814543

Pinna, C., Morazzoni, P., and Sala, A. (2017). Proanthocyanidins from Vitis vinifera inhibit oxidative stress-induced vascular impairment in pulmonary arteries from diabetic rats. Phytomedicine 25, 39-44. doi: 10.1016/j.phymed.2016. 12.015

Pons, Z., Margalef, M., Bravo, F. I., Arola-Arnal, A., and Muguerza, B. (2016). Acute administration of single oral dose of grape seed polyphenols restores blood pressure in a rat model of metabolic syndrome: role of nitric oxide and prostacyclin. Eur. J. Nutr. 55, 749-758. doi: 10.1007/s00394-015-0895-0

Poston, L., Briley, A. L., Seed, P. T., Kelly, F. J., Shennan, A. H., and Vitamins in Preeclampsia (Vip) Trial Consortium. (2006). Vitamin C and vitamin E in pregnant women at risk for pre-eclampsia (VIP trial): randomised placebo-controlled trial. Lancet 367, 1145-1154. doi: 10.1016/S0140-6736(06)68433-X

Poston, L., Chappell, L., Seed, P., and Shennan, A. (2011). Biomarkers of oxidative stress in pre-eclampsia. Pregnancy Hypertens. 1, 22-27. doi: 10.1016/j.preghy. 2010.10.009

Poudel, R., Stanley, J. L., Rueda-Clausen, C. F., Andersson, I. J., Sibley, C. P., Davidge, S. T., et al. (2013). Effects of resveratrol in pregnancy using murine models with reduced blood supply to the uterus. PLoS One 8:e64401. doi: 10.1371/journal.pone.0064401

Preuss, H. G., Wallerstedt, D., Talpur, N., Tutuncuoglu, S. O., Echard, B., Myers, A., et al. (2000). Effects of niacin-bound chromium and grape seed proanthocyanidin extract on the lipid profile of hypercholesterolemic subjects: a pilot study. J. Med. 31, 227-246.

Razavi, S. M., Gholamin, S., Eskandari, A., Mohsenian, N., Ghorbanihaghjo, A., Delazar, A., et al. (2013). Red grape seed extract improves lipid profiles and decreases oxidized low-density lipoprotein in patients with mild hyperlipidemia. J. Med. Food 16, 255-258. doi: 10.1089/jmf.2012. 2408

Renshall, L. J., Morgan, H. L., Moens, H., Cansfield, D., Finn-Sell, S. L., Tropea, T., et al. (2018). Melatonin increases fetal weight in wild-type mice but not in mouse models of fetal growth restriction. Front. Physiol. 9:1141. doi: 10.3389/ fphys.2018.01141

San Juan-Reyes, S., Gómez-Oliván, L. M., Islas-Flores, H., and Dublán-García, O. (2020). Oxidative stress in pregnancy complicated by preeclampsia. Arch. Biochem. Biophys. 681:108255. doi: 10.1016/j.abb.2020.108255

Sano, A., Uchida, R., Saito, M., Shioya, N., Komori, Y., Tho, Y., et al. (2007). Beneficial effects of grape seed extract on malondialdehyde-modified LDL. J. Nutr. Sci. Vitaminol. 53, 174-182. doi: 10.3177/jnsv.53.174

Sato, A., Nishioka, S., Kiuchi, M., Imada, Y., Makino, K., Nakagawa, K., et al. (2020). Grape extract from chardonnay seeds restores deoxycorticosterone acetate-saltinduced endothelial dysfunction and hypertension in rats. Biol. Pharm. Bull. 43, 59-67. doi: 10.1248/bpb.b19-00540 
Schoots, M. H., Gordijn, S. J., Scherjon, S. A., van Goor, H., and Hillebrands, J. L. (2018). Oxidative stress in placental pathology. Placenta 69, 153-161. doi: 10.1016/j.placenta.2018.03.003

Seely, E. W., and Ecker, J. (2014). Chronic hypertension in pregnancy. Circulation 129, 1254-1261. doi: 10.1161/CIRCULATIONAHA.113.003904

Shawwa, K., McDonnell, N. A., and Garovic, V. D. (2018). Pregnancy, preeclampsia, and brain. Hypertension 72, 1263-1265. doi: 10.1161/HYPER TENSIONAHA.118.11493

Shesely, E. G., Maeda, N., Kim, H. S., Desai, K. M., Krege, J. H., Laubach, V. E., et al. (1996). Elevated blood pressures in mice lacking endothelial nitric oxide synthase. Proc. Natl. Acad. Sci. U.S.A. 93, 13176-13181. doi: 10.1073/pnas.93. 23.13176

Shi, J., Yu, J., Pohorly, J. E., and Kakuda, Y. (2003). Polyphenolics in grape seeds-biochemistry and functionality. J. Med. Food 6, 291-299. doi: 10.1089/ 109662003772519831

Sibai, B. M. (2002). Chronic hypertension in pregnancy. Obstet. Gynecol. 100, 369-377. doi: 10.1016/s0029-7844(02)02128-2

Sibai, B. M., Lindheimer, M., Hauth, J., Caritis, S., VanDorsten, P., Klebanoff, M., et al. (1998). Risk factors for preeclampsia, abruptio placentae, and adverse neonatal outcomes among women with chronic hypertension. National Institute of Child Health and Human Development Network of Maternal-Fetal Medicine Units. N. Engl. J. Med. 339, 667-671. doi: 10.1056/ NEJM199809033391004

Sivaprakasapillai, B., Edirisinghe, I., Randolph, J., Steinberg, F., and Kappagoda, T. (2009). Effect of grape seed extract on blood pressure in subjects with the metabolic syndrome. Metabolism 58, 1743-1746. doi: 10.1016/j.metabol.2009. 05.030

Stanley, J. L., Andersson, I. J., Hirt, C. J., Moore, L., Dilworth, M. R., Chade, A. R., et al. (2012). Effect of the anti-oxidant tempol on fetal growth in a mouse model of fetal growth restriction. Biol. Reprod. 87, 1-8. doi: 10.1095/biolreprod.111. 096198

Sutton, A. L. M., Harper, L. M., and Tita, A. T. N. (2018). Hypertensive disorders in pregnancy. Obstet. Gynecol. Clin. North Am. 45, 333-347. doi: 10.1016/j.ogc. 2018.01.012

Tanbe, A. F., and Khalil, R. A. (2010). Circulating and vascular bioactive factors during hypertension in pregnancy. Curr. Bioact. Compd. 6, 60-75. doi: 10.2174/ 157340710790711737

Tropea, T., De Francesco, E. M., Rigiracciolo, D., Maggiolini, M., Wareing, M., Osol, G., et al. (2015). Pregnancy Augments G Protein Estrogen Receptor (GPER) induced vasodilation in rat uterine arteries via the nitric oxide - cGMP signaling pathway. PLoS One 10:e0141997. doi: 10.1371/journal.pone.0141997
Tropea, T., Renshall, L. J., Nihlen, C., Weitzberg, E., Lundberg, J. O., David, A. L., et al. (2020). Beetroot juice lowers blood pressure and improves endothelial function in pregnant eNOS. J. Physiol. doi: 10.1113/JP279655 [Epub ahead of print].

Varadharaj, S., Steinhour, E., Hunter, M. G., Watkins, T., Baran, C. P., Magalang, U., et al. (2006). Vitamin C-induced activation of phospholipase D in lung microvascular endothelial cells: regulation by MAP kinases. Cell Signal. 18, 1396-1407. doi: 10.1016/j.cellsig.2005.10.019

Vaughan, O. R., and Fowden, A. L. (2016). Placental metabolism: substrate requirements and the response to stress. Reprod. Domest. Anim. 51(Suppl. 2), 25-35. doi: 10.1111/rda.12797

Waldron, G. J., Ding, H., Lovren, F., Kubes, P., and Triggle, C. R. (1999). Acetylcholine-induced relaxation of peripheral arteries isolated from mice lacking endothelial nitric oxide synthase. Br. J. Pharmacol. 128, 653-658. doi: 10.1038/sj.bjp.0702858

Wang, L., Zhu, L. H., Jiang, H., Tang, Q. Z., Yan, L., Wang, D., et al. (2010). Grape seed proanthocyanidins attenuate vascular smooth muscle cell proliferation via blocking phosphatidylinositol 3-kinase-dependent signaling pathways. J. Cell Physiol. 223, 713-726. doi: 10.1002/jcp.22080

Woods, L., Perez-Garcia, V., and Hemberger, M. (2018). Regulation of placental development and its impact on fetal growth-new insights from mouse models. Front. Endocrinol. 9:570. doi: 10.3389/fendo.2018.00570

Zhang, H., Su, S., Yu, X., and Li, Y. (2017). Dietary epigallocatechin 3-gallate supplement improves maternal and neonatal treatment outcome of gestational diabetes mellitus: a double-blind randomised controlled trial. J. Hum. Nutr. Diet 30, 753-758. doi: 10.1111/jhn.12470

Zhu, F. Q., Hu, J., Lv, F. H., Cheng, P., and Gao, S. (2018). Effects of oligomeric grape seed proanthocyanidins on L-NAME-induced hypertension in pregnant mice: role of oxidative stress and endothelial dysfunction. Phytother. Res. 32, 1836-1847. doi: 10.1002/ptr.6119

Conflict of Interest: The authors declare that the research was conducted in the absence of any commercial or financial relationships that could be construed as a potential conflict of interest.

Copyright (c) 2020 Tropea, Greenwood, Sibley and Cottrell. This is an open-access article distributed under the terms of the Creative Commons Attribution License (CC BY). The use, distribution or reproduction in other forums is permitted, provided the original author(s) and the copyright owner(s) are credited and that the original publication in this journal is cited, in accordance with accepted academic practice. No use, distribution or reproduction is permitted which does not comply with these terms. 